\section{METÁFORAS TECNOCIENTÍFICAS EN EL DISCURSO MEDIÁTICO: ANÁLISIS HERMENÉUTICO E IMPACTO SOCIO-EDUCATIVO}

\author{
Elena Jiménez García \\ Universidad de Valladolid \\ elenajc@dlyl.uva.es \\ Juan R. Coca \\ Universidad de Valladolid \\ juancoca@soc.uva.es \\ Francisco J. Francisco Carrera \\ Universidad de Valladolid \\ franjosefran@dlyl.uva.es \\ Jesús Valero Matas \\ Universidad de Valladolid \\ valeroma@soc.uva.es
}

Cómo citar este artículo/Citation: Jiménez García, E.; Coca, J.R.; Francisco Carrera, F.J. y Valero Matas, J. (2014). "Metáforas tecnocientíficas en el discurso mediático: análisis hermenéutico e impacto socio-educativo". Arbor, 190 (769): a171. doi: http://dx.doi.org/10.3989/arbor.2014.769n5010

Recibido: 1 agosto 2013. Aceptado: 26 junio 2014.

RESUMEN: A lo largo de la historia de la lengua española, se ha hecho patente la preocupación por los usos lingüísticos y por su interpretación. Son muchos los numerosos estudios semánticos de los que disponemos, enfocados desde distintas lenguas. Partiendo del estudio de Lakoff y Johnson Metáforas de la vida cotidiana, podemos observar que las interpretaciones de algunas metáforas que se utilizan frecuentemente en lengua inglesa pueden ser interpretadas de igual manera en la lengua española. Para ello, hemos seleccionado algunos ejemplos de veintidós artículos de opinión, publicados en prensa escrita en España en el año 2012 y hemos observado que la diversidad de interpretaciones está basada en la creatividad y en la intencionalidad del hablante.

PALABRAS CLAVE: Metáfora; semántica; lengua; artículos de opinión.

\section{TECHNO-SCIENTIFIC METAPHORS IN THE MEDIA SPEECH: HERMENEUTIC ANALYSIS AND SOCIAL-EDUCATIONAL IMPACT}

Copyright: (C) 2014 CSIC. Este es un artículo de acceso abierto distribuido bajo los términos de la licencia Creative Commons Attribution-Non Commercial (by-nc) Spain 3.0.

ABSTRACT: A concern with language usage and interpretation has been apparent throughout the history of the Spanish Language. Numerous semantic studies are available focusing on a variety of languages. Taking a study of Lakoff and Johnson's Metaphors We Live By as our starting point, we can see how interpretations of certain metaphors commonly used in the English language can also be interpreted in Spanish. Thus, we have selected some examples from twenty-two opinion pieces, published in the Spanish press in 2012 and have observed the diversity of interpretations based on the writer's creativity and intentionality.

KEYWORDS: Metaphor; semantic; language; opinion piece. 


\section{INTRODUCCIÓN}

El uso de la metáfora en la lengua oral y escrita es un tema clásico de estudio que tiene gran interés a nivel filosófico, lingüístico, sociológico, político, etc. Dicho enfoque aporta gran información indirecta tanto del mensaje subyacente (y por tanto imaginario) como de los elementos fenoménicos que están funcionando en dicho proceso. Ello es así puesto que la metáfora es una forma de representar aspecto de la vida experiencia colectiva y de transmitir elementos ideológicos (Fairclough, 2001, p. 100). Ello hace que el concepto de metáfora pueda estar contenido dentro de la definición de imaginario social: esquema socialmente construido que nos permite percibir, explicar e intervenir en lo que en cada sistema social diferenciado se tenga por realidad (Pintos). Por lo tanto, podemos afirmar que el estudio de las metáforas en sociedad nos va a permitir también aproximarnos al conocimiento de los imaginarios sociales que están funcionando.

Las metáforas son estructuras que facilitan la comprensión conceptual y la estructuración del significado, ya que se proyecta dicho significado sobre otro, entendiéndolo desde el punto de vista biológico y espacial. Ello hace que el análisis de metáforas tenga una relevancia social, pero siempre y cuando seamos conscientes que la metáfora no se circunscribe al ámbito del lenguaje, sino que percola hacia nuestro pensamiento haciendo que el sistema conceptual que ponemos en funcionamiento constantemente, a nivel científico u ordinario, sea en buena medida metafórico.

Comprender los mecanismos de nuestra herramienta básica de comunicación (el lenguaje) supone, entre otros, un proceso de reflexión sobre el uso de la metáfora. Pues, según Lakoff y Johnson (1986) "la metáfora [...] impregna la vida cotidiana, no solamente el lenguaje, sino también el pensamiento y la acción", frente a aquellos otros que piensan que "pueden arreglárselas perfectamente sin metáforas" (p. 39). También Llamas Saíz (2005, p. 20) considera que "la metáfora es, pues, un asunto de designación, es decir, de uso, que plasma la creatividad lingüística de los hablantes. Dejando a un lado los valores expresivos y estéticos de la metáfora, esta se considera uno de los procedimientos del cambio semántico [...]". Por lo tanto, podemos afirmar que nuestro sistema conceptual es mayoritariamente de naturaleza metafórica.

La obra de Lakoff y Johnson, como han expuesto Iñesta y Pamies (2002), es problemática al ser de- masiado pobre y hace más complejo el análisis. De hecho afirman que "harían falta miles de metáforas estructurales para clasificar un corpus fraseológico real" (Iñesta y Pamies, 2002, p. 89), lo que hemos dicho que dificulta el análisis. Por ello, estos autores han establecido las categorías de modelos icónicos y archimetáforas siendo estas más abarcantes y globales. Recuérdese que, para estos autores españoles, en las archimetáforas pueden incluirse unidades fraseológicas que son de uso habitual en nuestra lengua.

Este trabajo de Lakoff y Johnson ha sido la base de otros muchos que tratan de explicar y desarrollar con ejemplos el uso, a veces "abusivo" de metáforas en la lengua habitual. Cuando hablamos de abuso, empleamos este término con un valor significativo positivo, es decir, nos referimos a las numerosas ocasiones que aparece la metáfora, muchas veces inconscientemente, en nuestro lenguaje y en nuestro pensamiento y, por lo tanto, en todos los registros lingüísticos. Por ello, y porque el estudio de Lakoff y Johnson está tratado desde la lengua inglesa, hemos querido hacer una indagación de los usos metafóricos en la prensa escrita española, como ejemplo específico y haciendo también un análisis socio-hermenéutico de la aplicación de dichas metáforas en el desarrollo y en la configuración actual de nuestra realidad social, centrándonos en una de las actividad más importantes en la actualidad: la tecnociencia. Además, y de un modo más concreto, nos planteamos el objetivo último de conocer unas metáforas poco trabajadas previamente en estudios de este tipo, puesto que los trabajos que conocemos al respecto centran su interés en el uso de las metáforas para el desarrollo de la ciencia (Balza-García, 2006; Bustos, 2000; Ciapuscio, 2011; Cuadrado, 2004; Fox Keller, 1995; Fuentes Julián, 1998; Palma, 2004 y 2005; Rivadulla, 2006). Gracias a ello buscamos reducir la visión negativa y la deriva excluyente que pueda estar presente en la divulgación de la ciencia y la tecnología.

\section{METODOLOGÍA}

La prensa escrita y concretamente los artículos de opinión implican varios procesos de creación lingüística, literaria, etc., en los que, evidentemente, se emplean metáforas de diversa tipología. El estudio sobre lo imaginario o, si se prefiere, sobre los imaginarios que han venido realizando autores tales como Castoriadis, Pintos, Baeza, Sánchez Capdequí, Beriaín, Coca, Carretero o Lizcano ha permitido mostrar que las metáforas son elementos comunicacionales que crean y configuran nuestra realidad al dotar de sig- 
nificado a nuestro entorno social. En línea con esto, y prestando especial atención al uso metodológico que Lizcano (1999 y 2006) hace de las metáforas (socio-análisis metafórico) como estructuras de análisis social, hemos pretendido desarrollar un análisis socio-hermenéutico de la realidad española. Para ello hemos extraídos de una selección de artículos de opinión publicados en distintos medios impresos en 2012 las metáforas fundamentales que nos explican el entorno español actual. En base a esto, la finalidad de este trabajo es ver la correspondencia y vigencia de algunas metáforas expuestas por Lakoff y Johnson en la sociedad española y hacer un análisis interpretativista de nuestra región.

\section{RESULTADOS Y DISCUSIÓN}

\section{La discusión es la guerra}

La metáfora "una discusión es una guerra" parece seguir vigente en el imaginario social de España. Esta metáfora aparece como algo que vivimos constantemente en nuestro "día a día", por ejemplo cuando estamos ante una confrontación dialéctica, y cuando consideramos a la persona que tenemos enfrente como un opuesto, utilizamos expresiones con vocabulario propio de la guerra. Véase algunos ejemplos:

"[...] lo que choca con la experiencia de todos los días". Millás, J.J. "Era tan normal”. El País. 8 de marzo de 2012.

Chocar aparece con el significado de combatir o enfrentarse. Lakoff y Johnson lo tratan desde el uso lingüístico de la discusión, pero realmente se ha hecho extensivo a otras expresiones, cuyos significantes aparecen ilustrados en los siguientes ejemplos:

"Por el tono de algunas declaraciones, le veo ganas al ministro de Industria de amotinarse contra los mineros". Rivas, M. "La conductora". El País. 29 de junio de 2012.

"[...] se han declarado en contra [...]". Montero, R. "Padres". El País. 25 de junio de 2012.

"Los hijos no deberían ser munición de ataque". Montero, R. "Padres". El País. 25 de junio de 2012.

"Obama puede ser derrotado en las urnas". Juliana, E. "La metáfora Montoro". La Vanguardia. 21 de julio de 2012.

"Europa puede ser la tumba política de Barack Obama”. Juliana, E. "La metáfora Montoro". La Vanguardia. 21 de julio de 2012.
"El presidente ha aprovechado que la discusión central giraba en torno al proceso de construcción e integración europea”. Cruz, M. "Rajoy: 'Ser pequeño y estar en procesos de división no tiene sentido'”. EI Mundo. 19 de diciembre de 2012.

Esta metáfora de la discusión como una guerra se mantiene en el establecimiento de las relaciones sociales. En este sentido la interpretación que se puede hacer de esta realidad se concatena claramente con las estructuras de poder interhumanas. Recuérdese que, como bien ha expuesto Manuel Castells (2009, p. 257), el poder se va construyendo a base de conformar nuestra toma de decisiones, bien por un proceso coercitivo, bien por la construcción de significado (que es lo que nos ocupa en este trabajo) o, por último, por una confluencia de ambas.

Pues bien, supongamos que en una relación comunicativa entre dos personas uno de los emisores expone un discurso. Dicho discurso implica, según los imaginarios desarrollados en los medios de comunicación, cierta afirmación de un determinado estatus social: padre, madre, profesor, ministro, juez, experto, etc. Por otro lado tenemos, supongamos, un disensor que no concuerda con el discurso emitido y blande una espada dialéctica que busca asimilar la postura de poder del otro a través de la confrontación. Esta estructura de relación discursiva destructiva implicaría la desaparición de uno de los dos contendientes por el sometimiento a la "razón" emitida por el otro. Esta construcción de la comunicación interhumana asume elementos propios del racionalismo donde la razón era aquel elemento superior que estaba por encima de la animalidad de los sentimientos. Parece, entonces, que se continúa con este elemento racionalista al considerar que el poseedor de "la razón" discursiva es el vencedor de la contienda.

Lo antedicho se ejemplifica especialmente en el ámbito científico-tecnológico (o mejor dicho, tecnocientífico), puesto que en la discusión tecnocientífica "se supone que el interés es la búsqueda de la verdad y el progreso de la ciencia" (Gramsci, 1971, p. 26). El problema es que el propio Gramsci fue consciente que la contienda dialéctica de la tecnociencia se transforma en judicial donde hay un imputado que debe ser analizado y juzgado (Gramsci, 1971). Un ejemplo de esto lo vemos en el extracto de un artículo el papel de los científicos en las situaciones de catástrofe, donde se muestra que en la discusión hay claros ganadores y vencidos. 
"Al cabo de un año, las señales premonitorias reaparecieron y se produjo una intensa discusión entre los científicos. Acabó predominando el criterio de los que pensaban que no podía producirse un terremoto mayor que el del año anterior, que ya se había liberado una gran cantidad de energía. Se decidió no evacuar. Uno de los científicos derrotados estaba en casa cuando observó que los peces saltaban de la pecera. Cogió a su nieto y corrió al parque más cercano." Pérez Oliva, M. "El delicado papel de la ciencia en las catástrofes". El País. 01 de noviembre de 2012.

Esta realidad de ausencia de debates también la podemos ver en la siguiente afirmación:

"En ciencia no se vota, se llegan a consensos o a disensos comunicados en lenguaje científico. Fuera de los canales científicos, para la mayoría de la comunidad científica "no hay discusión"”. Lobera, J. "El Debate: Contradicciones entre ciencia y democracia. ¿Mayoría absoluta o minoría cualificada?”. El Foro CTS. 16 de agosto de 2011

Lobera, evidentemente, pretende decir que lo que se establecen son consensos que, finalmente, son los que son transmitidos. El problema es que, tal y como afirma Lobera, la comunidad científica no es permeable a nada externo. Ello implica que el discurso que sale del sistema tecnocientífico es, en general, unívoco.

\section{Metáforas orientacionales y de geolocalización}

Las metáforas orientacionales dan a un concepto una orientación espacial y tienen una base en nuestra experiencia física y cultural. Por ello es posible afirmar que esta orientación del hombre se basa en la idea de que el hombre es un microcosmos inserto "en su proporción, en su analogía, en la armonía con el cosmos, en el orden universal" (Beuchot, 2011, p. 36).

Según Iñesta Mena y Pamies Beltrán (2002, p.57), Lakoff y Johnson "abordan el significado considerando las capacidades biológicas y las experiencias físicas o sociales que nos son propias, como series que funcionamos en un entorno. [...] Nuestra orientación en el espacio, la situación de los objetos en el mundo físico, el movimiento, etc. son fuentes de metáforas: a partir de lo más cercano, experiencial, se explicaría lo más lejano". Así se facilita la interpretación de realidades abstractas, tomando algo concreto de la experiencia personal.

Estas metáforas implican una socio-hermenéutica del entorno. Una reinterpretación vertical u horizon- tal, al tiempo que paradójica, de la realidad donde tanto lo superior como lo anterior o primero es aquello que nos ilumina, lo mejor, lo idóneo o lo que nos domina, controla y obliga. Por ejemplo:

"[...] irás derecho al infierno de la vulgaridad". López Iturriaga, M. "Pijas que nos enseñan a poner la mesa”. El País. 29 de junio de 2012.

En este caso vemos claramente cómo en esta metáfora se relaciona la idea del infierno (situado siempre abajo) con la vulgaridad, entendida esta en sentido peyorativo y con un mensaje condicionador del comportamiento social. Es necesario, por tanto, no caer en dicha vulgaridad y ser especial.

Asimismo, lo racional, lo mental o lo psíquico lo solemos localizar arriba, mientras que lo propio de nuestros sentimientos estará abajo. De ahí que sea posible colegir que la actividad tecnocientífica será situada en la parte superior convirtiéndose en un oráculo que dictamina nuestro desarrollo epistémico. Esta idea la podemos ejemplificar en la actualidad en la constante reconversión de las ciencias humanas y sociales imitando la estructura interna de las ciencias experimentales o factuales. Ello es así puesto que estas últimas, junto con las ciencias formales, se localizan en la parte superior (son supuestamente más racionales, más objetivas, etc.) en cambio las ciencias sociales y humanas están más próximas al mundo de los sentimientos $y$, por tanto, son localizadas por debajo.

En nuestro rastreo de los medios de comunicación hemos podido comprobar que, tal y como indicamos previamente, en las metáforas orientacionales existe una significación doble en la que las localización arriba y delante es empleada en sentido positivo. Gracias a ellas se resaltan las grandezas y relevancias de determinadas investigaciones, disciplinas, etc. Por ejemplo:

"Nuestro modelo es un gran paso [...]". Nieves, J. M. “Crean el "Google Maps» del metabolismo humano". ABC. 05 de marzo de 2013.

"Un grupo de investigadores vascos ha abierto una puerta para que el cáncer de colon humano". Viñas, S. R. "Esperanza contra el cáncer de colon". El Mundo. 11 de marzo de 2013.

"[...]la medicina confrontada a los enigmas, la medicina como un modo de ver y de pensar hasta el fondo de lo que vemos pero que no entendemos y que, por ello, nos resulta tan extraño". Antich, J. "La medicina como metáfora". La Vanguardia. 3 de septiembre de 2012. 
No obstante, también encontramos un sentido negativo en el discurso, donde lo que asciende puede ser lo negativo que afecta y condiciona a lo que está por encima, haciendo que la hermenéutica subyacente trasluce un entorno de degradación de los elementos positivos:

"El crecimiento de un tumor depende de esta interacción”. Viñas, S. R. "Esperanza contra el cáncer de colon". El Mundo. 11 de marzo de 2013.

"[...] los ortopédicos tropezones [...]". Montero, R. "Todas". El País. 5 de marzo de 2012.

"España, agarrada al arbusto que sobresale en el abismo [...]". Juliana, E. "La metáfora Montoro". La Vanguardia. 21 de julio de 2012.

“[...] no se resquebrajará la dignidad de los vivos [...]". Regás, R. "Siniestra ley del aborto". El Mundo.30 de julio de 2012.

"Impresionante polvareda la que ha levantado el informe de la Real Academia sobre el Sexismo Lingüístico". Montero, R. "Todas". El País. 5 de marzo de 2012.

"[...] es una verdad que cae por su propio peso". Regás, R. "Siniestra ley del aborto". El Mundo.30 de julio de 2012.

Comprobamos, entonces, que la ciencia está siendo comunicada o divulgada mostrando sus grandes avances y localizándolos en el espacio imaginario que está delante o arriba. Esta concepción geo-metafórica se produce en todos los discursos emitidos, directa o indirectamente, por los distintos tipos de ciencias (formales, factuales, sociales y humanas). No obstante, podemos afirmar que la imagen discursiva general de contracción del concepto ciencia a las formales y experimentales, excluyendo a las demás, evidencia una hermenéutica social reduccionista de la ciencia. Ello es debido a la asunción imaginaria de una estructura vertical de las ciencias en la que las formales y las factuales se localizan arriba y dominan a las demás.

Como es bien sabido, esta concepción se ha originado gracias -en buena medida- a la corriente positivista de la ciencia y se ha mantenido hasta la actualidad incorporándose al imaginario colectivo. De hecho, es fácil comprobar cómo los científicos de la educación se consideran maestros o profesores y asumen que el concepto de ciencia hace referencia a exclusivamente a las factuales y formales.

Tras lo dicho, parece que el uso metafórico en prensa escrita tiende al significado negativo en los ejemplos expuestos y hacia una socio-hermenéutica que puede ser denominada como escatológica de la degradación proveniente de esta significación de geo-localización. Asimismo, las metáforas a las que hemos hecho referencia indican que el discurso sobre la ciencia asume elementos culturales generales $y$, además, estructuran el conocimiento relacionado con la ciencia de un modo verticalizado y geo-localizado en una posición superiorizada con respecto a otros ámbitos de la cultura.

\section{Elementos ontológicos}

Lakoff y Johnson (1986) han establecido un tercer grupo de metáforas, las ontológicas, en las que se consideran acontecimientos, emociones, ideas, etc., tal y como si fuesen entidades y substancias (1986, p. 64). Por lo tanto, y dada dicha substancialidad, el discurso que se genera es inmutable y no procesual. Este hecho tiene una especial relevancia en el discurso que se desarrolla sobre la actividad tecnocientífica y sobre sus hallazgos. Tanto es así que incluso podemos llegar a afirmar, como veremos en un ejemplo que a nuestro juicio es paradigmático, que el discurso sobre la tecnociencia se está convirtiendo, cada vez más, en una quimera, en un constructo social que fomenta un imaginario mágico y fantástico de los resultados científicos.

Estas afirmaciones las podemos ejemplificar en el descubrimiento de la medusa Turritopsis nutricula de la cual se dice que es "inmortal". En este sentido, se ha llegado a escribir que "Turritopsis nutricola es capaz de conseguir esta proeza porque ha descubierto la manera de modificar sus células una vez estas se han diferenciado" Nieves, J. M. "Una medusa inmortal se extiende por todos los océanos de la Tierra". ABC. 29 de enero de 2009.

Otro ejemplo interesante nos lo encontramos en la información sobre Australopithecus sediba del cual se afirma que es una "extraña criatura" Nieves, J. M "Australopithecus sediba: ¿el eslabón perdido?", $A B C .11$ de abril de 2013. Mientras que en otro reciente artículo sobre las supernovas se afirma lo siguiente: "Pero ha de pasar tanto tiempo, que ninguna mente humana lo puede comprender". Gilarte Fernández, G. "Supernovas, la mayor catástrofe del Universo", ABC. 18 de abril de 2013. Incluso algunos reputados especialistas y divulgadores, tales como Xurxo Mariño, han afirmado que estamos "inventando gran parte del mundo que percibimos". Efe "Destruimos un $3 \%$ de neuronas a lo largo de la vida". La Razón. 20 de marzo de 2013. 
Estos y otros ejemplos nos muestran como a menudo se traslada la información científica, y por tanto real, al mundo imaginario e irreal con el fin de suscitar interés en el lector. El problema está en que estas metáforas configuran, tal y como hemos dicho, un mundo gobernado, directa o indirectamente, por los procesos mágicos y esotéricos. De ahí que incluso la tecnociencia divulgada se pueda estar convirtiendo en ciertas ocasiones en una pseudo-religión en la cual se generan constantemente un conjunto de "milagros" provenientes de la caprichosa diosa naturaleza. Ello nos conduce a alguna de las afirmaciones expuesta por Arthur Clarke quien en 1989 afirmó que toda tecnología que esté suficientemente avanzada llega a ser indistinguible de la magia (Clarke, 1989), algo a lo que se sumó Stanley Schmidt (1993) al afirmar que muchas personas que usan nuestra tecnología pueden tener ciertas dificultades para distinguirla de la propia magia.

Ello comporta la constitución de un mundo ficcional que se encadena con las imágenes que sociedad va a tener sobre el futuro del mundo (Beckert, 2013) y sobre la generación de expectativas colectivas hacia la representación mental de la actividad tecnocientífica. Por ello, la toma de decisiones que puedan traer consigo la implantación y generalización de este tipo de metáforas podría generar el desarrollo de un modelo operativo de toma de decisiones mediado por una ficcionalización, permítasenos decirlo así, de la naturale$z a$, de nuestro conocimiento del mundo natural y del impacto de este en la sociedad.

\section{CONSECUENCIAS DE ESTE DISCURSO}

El filósofo español Xavier Zubiri nos ha mostrado en sus primeros escritos cómo la virtualidad es un elemento fundamental que caracteriza al "ser intencional", de ahí que este no sea realidad, sino -efectivamente- virtualidad (Zubiri, 1999). Dicha virtualidad está inscrita dentro de la irrealidad; es decir, de lo irreal (Zubiri, 1987).Asimismo, este autor nos muestra que hay, según él, tres modos fundamentales de lo irreal: el espectro, la ficción y la idea.

"Estos tres modos se caracterizan, el primero [el espectro] por ser una proyección, en cierto modo ad extra, en la realidad sustantiva, de unas ciertas notas que no le pertenecen de suyo; la ficción se caracteriza por construir cosas, concretamente cosas distintas de las que vemos en la realidad; y la idea consiste en idear de una manera exacta y definida aquello que constituye o el contenido de la realidad, o construcciones puramente ideales aplicadas a las ideas" (Zubiri, 2005, pp. 68 ss.)
Estos tres modos de irrealidad implican, sobre todo la ficción y la idea, que esta irrealidad sea posibilidad en el sentido de creatividad. De hecho, la irrealidad es el proyecto de una realidad. De ahí que la irrealidad es cuasi creación, puesto que el ser humano se apoya en lo real para hacerse a sí mismo y, gracias a dicha irrealización, el ser humano llena de contenido el espacio del sentir que deja la realidad en nosotros.

Xavier Zubiri, además, ha expuesto que en la ficción, o mejor dicho, que en el mundo ficcional "no se finge "la" realidad, se finge tan solo que "la" realidad sea "así". Es el "cómo" sería "la" realidad, es decir, cómo sería la cosa en realidad" (Zubiri, 1982, p. 99). Dicho de otro modo, se trata en saber "cómo" se estructura lo real en creación libre, por lo tanto es la actualización de la realidad en ficción, no la ficción de la realidad. Se trata de conceptuar "cómo" sería lo real en realidad.

"El hombre, efectivamente, se figura ser de una cierta manera y hace la experiencia de sí mismo. Y esa experiencia de sí mismo es, a última hora, el eje cardinal de toda la integración de lo real y de lo irreal" (Zubiri, 2005, p. 197).

Partiendo de estas premisas podemos volver, entonces, a nuestro análisis socio-hermenéutico de las metáforas comunicacionales, las cuales trabajan "con la mostración equívoca de la diferencia mediante la aproximación ficticia" (Maillard, 2006, p. 354).

En este sentido, las metáforas que hemos ido exponiendo configuran un entorno imaginario muy determinado de la actividad científico-tecnológica. En él los nuevos avances parecen ser mágicos en lugar de ser fruto del quehacer humano. Por otro lado, también vemos que los medios de comunicación expresan la generación de un saber verticalizado que transmite un imaginario de superioridad de este tipo de conocimiento frente a los demás. Por último vemos también que parece producirse un discurso unívoco sobre lo científico. Estos tres elementos metafóricos mantienen, sin ninguna duda, la concepción tradicionalista y positivista de la ciencia y la tecnología. De ahí que la producción de esta actividad pudiera ser concebida alejada y despreocupada de la problemática social que tanto nos condiciona.

Estas afirmaciones tienen claras consecuencias sociales y educativas. Transmiten una concepción alejada de la actividad tecnocientífica que, presumiblemente, condicionará el acercamiento de los adolescentes a este ámbito laboral. Además, incrementa el nivel de desinterés por esta, puesto que 
implica la necesidad de desterritorialización para poder alcanzar este "mundo" localizado en una esfera superior. No obstante, como es bien sabido, nuestra sociedad está cada vez más tecnocientíficamente condicionada. Ello trae consigo que nuestra población será incapaz de analizar los beneficios y los perjuicios que puedan generar las nuevas tecnologías, lo que facilita la posibilidad de alienación y manipulación.

Por ello parece que resulta innegable hacer un doble esfuerzo en dos líneas diferentes y muy marcadas. La primera en una formación solvente hacia los comunicadores que les permita reducir este tipo de alteraciones divulgativas y espectaculares, que lo único que generan es una hipertrofiación de elementos minoritarios en la actividad tecnocientífica. Asimismo, ello reducirá la percepción negativa del imaginario tecnocientífico verticalizado y unívoco del que hemos hablado. De ahí que parece que tiene cierta lógica que se reducirá la falta de vocaciones científicas a la que nos vemos sometidos en la actualidad. Recuérdese que este hecho puede traer consigo graves y peligrosas consecuencias en nuestro mercado laboral futuro.

La segunda línea de trabajo estará relacionada con la formación de los docentes de infantil y primaria. En este sentido proponemos un enfoque didáctico un tanto diferente al que se está desarrollando en los últimos años. Generalmente se ha venido planteando una didáctica referida fundamentalmente a los contenidos que los docentes tienen que poner en marcha en su ámbito laboral. Ahora bien, consideramos que sería beneficioso aportar una serie de contenidos referidos a la generación de una didáctica de las ciencias (entendidas estas en el sentido más amplio del término) que permita atender a las nuevas realidades tecnocientíficamente condicionadas en las que vivimos. De esta manera será más fácil poder minimizar los riesgos inherentes a las decisiones y actuaciones sociales inconscientes e irracionales, propias de una actividad mágica. Por otro lado, una transformación en los contenidos de los grados en educación permitiría que la utilización de las metáforas en la didáctica de las ciencias (Martín Gordillo, 2003) tengan contenido educativo real y no se conviertan en transmisores de un imaginario pernicioso de la actividad tecnocientífica. Ello sucede así, tal y como también ha detectado Sánchez Upegui (2008) cuando la metáfora empleada no tiene intención di- dáctica o educativa y se limita a ser un elemento autorreferencial y, si se me permite, excluyente.

La formación completa y transdisciplinar es, sin ninguna duda, la herramienta más eficaz para poder gestionar nuestros procesos de irrealización propios. De este modo evitamos quedarnos en un mundo ideático y ficcional, y somos capaces de volver a la realidad tras pasar por ese mundo, algo obligado, dado que es la fuente de nuestra propia creatividad.

\section{CONCLUSIONES}

Es evidente el uso inconsciente de metáforas en el registro periodístico. En este artículo únicamente hemos dado una visión general y solo hemos planteado algunos ejemplos que se hacen patentes en los artículos de opinión que hemos elegido al azar entre muchos de los publicados en la prensa española durante el año 2012, principalmente.

De este modo, llegamos a las siguientes conclusiones:

1. Se trata de usos lingüísticos actuales, que se dan tanto en lengua escrita como en lengua hablada.

2. Son ejemplos que se hacen extensivos al registro coloquial de cualquier hablante, ya que el lenguaje que se utiliza en estos textos va dirigido a la mayoría de la población y, aunque están a caballo entre lo literario y lo científico, es necesario que el periodista utilice un lenguaje estándar para llegar a cualquier lector.

3. Esta panorámica nos confirma que no solo están presentes los usos metafóricos en las expresiones en la lengua inglesa, como hacen constar Lakoff y Johnson en su trabajo, sino que también se dan, a veces de forma abusiva, en los usos lingüísticos del español.

4. Además, estos ejemplos provocan nuevas creaciones lingüísticas y nuevas significaciones para ellas en cualquier lengua viva, a pesar de las consecuencias que pueda traer consigo. Pero la lengua se transforma diacrónicamente y evoluciona y son los hablantes dueños de ella.

5. Desde la perspectiva interpretativa, observamos que la intencionalidad tiene un factor irreal, es decir, implica ficción e idea en el sentido creativo. Esto supone una sólida formación lingüística del hablante, lo que genera un incremento intelectual de interpretación. 
Balza-García, R. (2006). La abstracción científica y la posibilidad metafórica. Bachelard y los fundamentos epistemológicos de la metáfora. Revista de filosofía, 54 2, pp. 9-38.

Beckert, J. (2013). Imagined futures: fictional expectations in the economy. Theory and Society, 42, pp. 219-240. http://dx.doi.org/10.1007/s11186013-919

Beuchot, M. (2011). Metáforas de nuestra vida. Antropología e interpretación. Huelva: Hergué Editorial.

Bustos, E. (2000). La metáfora. Ensayos transdisciplinares. Madrid: Fondo de Cultura Económica.

Castells, M. (2009). Communication Power New York: Oxford University Press.

Chaparro Lillo, J. (2010). El juego como metáfora de libertad y responsabilidad. La ética hermenéutica de Gadamer (Tesis doctoral inédita). Universidad de Valencia, Valencia.

Ciapusdio, G. E. (2011). De metáforas durmientes, endurecidas y nómades: un enfoque lingüístico de las metáforas en la comunicación de la ciencia. Arbor, 187, 747, pp. 89-98. http://dx.doi. org/10.3989/arbor.2011.747n1010

Clarke, A.C. (1989). Astounding days: the science fictional autobiography. Londres: Victor Gollanz Ltd.

Cuadrado Esclapez, G. (2004). Metáfora, ciencia y cultura: propuesta de una nueva tipología para el análisis de la metáfora científica. Ibérica, 7, pp. 53-70.

Fairclough, N. (2001). Language and Power. Essex (UK): Pearson Education.

Fillmore, C. (1982). Frame semantics. En Linguistic Society of Korea (ed.). Linguistics in the morning calm. Selected papers from SICOL 1981. Seoul: Hanshin Publishing, pp. 111-137.

Fillmore, C. (1985). Frames and semantics of understanding. Quaderni di Semantica, 6, pp. 222-254.

Fox Keller, E. (1995). Refiguring Life. Metaphors of Twentieth-Century Biology. New York: Columbia University Press.

Fuentes Julián, I. P. (1998). Entre la realidad y la ficción, la metáfora como recurso expositivo para la ciencia. Museo, 3, pp. 71-94.
Gramsci, A. (1971). El materialismo histórico y la filosofía de Benedetto Croce. Buenos Aires: Ediciones Nueva Visión.

Herrera Gómez, M. (2012). Redes sociales: de metáfora a paradigma. Barcelona: Furtwangen.

Iñesta Mena, E. M. y Pamies Beltrán, A (2002). Fraseología y metáfora: aspectos tipológicos y cognitivos. Granada: Método Ediciones.

Lakoff, G. y Johnson, M. (1986). Metáforas de la vida cotidiana. Madrid: Cátedra.

Lizcano, E. (1999). La metáfora como analizador social. Empiria. Revista de Metodología de Ciencias Sociales, 2, pp. 29-60.

Lizcano, E. (2006). Metáforas que nos piensan. Sobre ciencia, democracia y otras poderosas ficciones. Madrid: Ediciones Bajo Cero-Traficantes de sueños.

Llamas Saíz, C. (2005). Metáfora y creación léxica. Pamplona: Eunsa.

Lobera, J. (2011, 16 de agosto). El Debate: Contradicciones entre ciencia y democracia. ¿Mayoría absoluta o minoría cualificada? Recuperado de http:// www.revistacts.net/elforo/408-el-debate-contradicciones-entre-ciencia-ydemocracia-imayoria-absoluta-o-minoria-cualificada

Maillard, C. (2006). Metáfora. En: Ortiz Osés, A. y Lanceros, P. (dirs.) Diccionario de Hermenéutica. Una obra interdisciplinar para las ciencias humanas. Bilbao: Universidad de Deusto, pp. 352-357.

Martín Gordillo, M. (2003). Metáforas y simulaciones: alternativas para la didáctica y la enseñanza de las ciencias. Revista Electrónica de Enseñanza de las Ciencias, 2, 3, pp. 377-398.

Nagy, W. (1974). Figurative Patterns and Redundancy in the Lexicon (Tesis doctoral inédita). University of California, San Diego.

Palma, H. A. (2004). Metáforas en la evolución de la ciencia. Buenos Aires: Jorge Baudino Ediciones.

Palma, H. A. (2005). El desarrollo de las ciencias a través de las metáforas: un programa de investigación en estudios sobre la ciencia. Revista Iberoamericana de Ciencia, Tecnología y Sociedad, 6, 2, pp. 45-65.
Piñero Moral, R. I. (2008). Aciertos de metáfora. Salamanca: Luso-española de ediciones.

Reddy, M. (1993). The Conduit Metaphor A case of frame conflict in our language about language. En Ortony, A. (ed.) Metaphor and Thought. Cambridge: Cambridge University Press, pp. 164-201.

Rivadulla, A. (2006). Metáforas y modelos en ciencia y filosofía. Revista de filosofía, 31, 2, pp. 189-202.

Sánchez Upegui, A. A. (2008). El uso de metáforas en tres artículos académicos de educación virtual. Lingüística y literatura, 53, pp. 159-179.

Santos Domínguez, L. A. y Espinosa Elorza, R. M.a (1996). Manual de semántica histórica. Madrid: Síntesis.

Schmidt, S. (1993). Magic. Analog: Science Fiction and Fact, CXIII, 11, pp. 4-12.

Zubiri, X. (1982). Inteligencia y logos. Madrid: Alianza/Sociedad de Estudios y Publicaciones.

Zubiri, X. (1987). Sobre el hombre. Madrid: Alianza/Sociedad de Estudios y Publicaciones.

Zubiri, X. (1999). Primeros escritos (19211926). Madrid: Alianza/Fundación Xavier Zubiri.

Zubiri, X. (2005). El hombre: lo real y lo irreal. Madrid: Alianza/Fundación Xavier Zubiri.

\section{Artículos seleccionados:}

Antich, J. "La medicina como metáfora". La Vanguardia. 3 de septiembre de 2012. Recuperado de http://www. lavanguardia.com/opinion/articulos/20120903/54344476771/la-medicina-como-metafora-xavier-antich.html

García Garzón, J. I. "La ciudad de las mujeres". 17 de agosto de 2012. Recuperado de http://www.arndigital.com/culturay-sociedad/opinion/246/la-ciudad-delas-mujeres/

Gilarte Fernández, G. "Supernovas, la mayor catástrofe del Universo", $A B C .18$ de abril de 2013. Recuperado de http:// www.abc.es/ciencia/20130418/abcisupernovas-mayor-catastrofe-universo-201304181013.html 
Granados Gámez, F. “Artículo de opinión: Algo más que una mera fecha: 25 de noviembre, día internacional contra la violencia hacia las mujeres". 29 de noviembre de 2012. Recuperado de http://maracena.ideal.es/ actualidad/1234-articulo-de-opinionalgo-mas-que-una-mera-fecha-25-denoviembre-dia-internacional-contra-laviolencia-hacia-las-mujeres.html?tmpl =component $\&$ print=1\&layout=default \&page

Juliana, E. "La metáfora Montoro". La Vanguardia. 21 de julio de 2012. Recuperado de http://www.lavanguardia.com/opinion/articulos/20120721/54328001560/enric-juliana-la-metafora-montoro.html

Lindo, E. "La becaria de turno". El País. 10 de febrero de 2012. Recuperado de http://elpais.com/elpais/2012/02/10/ opinion/1328892486_756729.html

Lindo, E. "Quiero". El País. 6 de marzo de 2012. Recuperado de http:// elpais.com/elpais/2012/03/06/opinion/1331055728 922838.html

López Iturriaga, M. "La mujer que hablaba con los inodoros". El País. 1 de febrero de 2012. Recuperado de http:// elpais.com/elpais/2012/02/01/gente/1328099718_308414.html

López Iturriaga, M. "Pijas que nos enseñan a poner la mesa". El País. 29 de junio de 2012. Recuperado de http:// elpais.com/elpais/2012/06/29/gente/1340982682_509357.html

Mandianes, M. J. "Esclavas del sexo". 30 de julio de 2012. Recuperado de http:// reinaloba.wordpress.com/2012/07/30/ esclavas-del-sexo/\#more-229

Mariño, X. "Destruimos un 3\% de neuronas a lo largo de la vida". La Razón. 20 de marzo de 2013. Recuperado de http:// www.larazon.es/detalle_normal/noticias/1564539/destruimos-un-3-de-neuronas-a-lo-largo-de-la\#.UcCaefm1nJ

Millás, J. J. "Era tan normal”. El País. 8 de marzo de 2012. Recuperado de http:// elpais.com/elpais/2012/03/08/opinion/1331210676_259306.html

Montero, R. "Padres". El País. 25 de junio de 2012. Recuperado de http:// elpais.com/elpais/2012/06/25/opinion/1340626876_185547.html

Montero, R. "Todas". El País. 5 de marzo de 2012. Recuperado de http:// elpais.com/elpais/2012/03/05/opinion/1330951227_921857.html

Nieves, J. M. "Australopithecus sediba: ¿el eslabón perdido?". ABC. 11 de abril de 2013. Recuperado de http:// www.abc.es/ciencia/20130411/abciaustralophitecus-sediba-eslabon-perdido-201304111530.html

Nieves, J. M. "Crean el "Google Maps» del metabolismo humano". $A B C .5$ de marzo de 2013. Recuperado de http://www.abc.es/ciencia/20130305/ abci-crean-google-maps-metabolismo-201303050948.html

Nieves, J. M. "Una medusa inmortal se extiende por todos los océanos de la Tierra". ABC. 29 de enero de 2009. Recuperado de http://www.abc.es/20090129/ nacional-sociedad/medusa-inmortalextiende-todos-200901290005.html
Posadas, C. "Mujer tenías que ser". XI-Semanal. 5 de junio de 2011. Recuperado de http://www.finanzas.com/xl-semanal/firmas/20110605/magazine-firmaspequenas-infamias-mujer-2175.html

Regás, R. "Siniestra ley del aborto". El Mundo. 30 de julio de 2012. Recuperado de http://www.elmundo.es/blogs/elmundo/ellas/2012/07/30/siniestra-ley-delaborto.html

Rivas, M. "La conductora". El País. 29 de junio de 2012. Recuperado de http:// elpais.com/elpais/2012/06/29/opinion/1340979998_922602.html

Serrano, M. del M. "La inseguridad económica y laboral desprotegen a la mujer". 22 de noviembre de 2012 . Recuperado de http://huelvaya.es/2012/11/22/articulo-de-opinion-la-inseguridad-economica-y-laboral-desprotegen-a-la-mujer/

Torres, M. "8 de marzo". El País. 7 de marzo de 2012. Recuperado de http:// elpais.com/elpais/2012/03/07/opinion/1331118161_554556.html

Torres, M. "Olé faena”. El País. 5 de septiembre de 2012. Recuperado de http:// elpais.com/elpais/2012/09/05/opinion/1346854961_147750.html

Viñas, S. R. "Esperanza contra el cáncer de colon". El Mundo. 11 de marzo de 2013. Recuperado de http://www.elmundo. es/elmundo/2013/03/11/paisvasco/1362997394.html 